\title{
Consumer Perception of Tactile Packaging: A Research Study on Preferences of Soft Touch \& Hi Rise Coatings in Cosmetic Packaging
}

\section{Malcolm G. Keif, Ph.D.}

California Polytechnic State University

Graphic Communication Department mkeif@calpoly.edu

\author{
Colleen Twomey \\ California Polytechnic State University \\ Graphic Communication Department \\ ctwomey@calpoly.edu
}

Andrea Stoneman

California Polytechnic State University

Graphic Communication Department

astonema@calpoly.edu

\begin{abstract}
A choice-based conjoint study was conducted sampling 400 individuals to determine their preference for Soft Touch and raised tactile coatings, which are sometimes called Hi Rise or profile coatings. Soft Touch coatings have a velvety, warm feel to them, and Hi Rise coatings simulate embossing with a glossy appearance to them. Both are considered tactile coatings, engaging the sense of touch.

Demographic profile data, level of agreement about statements related to cosmetic packaging and packaging choice set selections were collected. The conjoint sets contained three attributes: design color, tactile coatings, and price.

Design choice was split. Approximately half of the respondents preferred a black design and half preferred a white design. There was no statistically significant difference between the design choices. As anticipated, respondents preferred cheaper prices.

Regarding the tactile coatings, respondents preferred the Hi Rise coating to no coating at all and to the Soft Touch coating. However, when including the interaction of price, the Hi Rise coating did not support a $5 \%$ price increase. It did show evidence of some price increase, but not $5 \%$.

The Soft Touch coating was also preferred over no tactile coating by respondents. It showed a statistical interaction effect with price, possibly because of perceived value. Soft Touch tactile coatings were preferred by respondents over no tactile coating, even at a $5 \%$ price increase.
\end{abstract}

KEYWORDS: $\quad$ tactile, coating, hi rise, soft touch, raised, profile, packaging 


\section{INTRODUCTION \& PURPOSE}

Consumers like to touch before they buy. It is believed that engaging the sense of touch influences sales in a positive manner (Saastamoinen, 2012) (Klatzky \& Peck, 2012) (Peck \& Childers, 2003) (Peck \& Wiggins, 2006). It is often assumed that the more consumers handle a product, the more likely they will purchase that product. This study addresses the question: Is there evidence that tactile packaging is preferred by consumers and that it increases sales?

Varnishes and coatings are used frequently in packaging, both for protection and for graphic enhancements. Recently, coatings are being applied to packaging to add functionality beyond protection, enhancing the user experience and incorporating a tactile effect. Using Soft Touch coatings, a velvet or matte feel can be achieved. Using a Hi Rise coating, a patterned coating that offers a raised, glossy image to enhance the graphics, an embossed feel can be achieved without the cost of tooling or offline processes. Tactile patterns can be made to match graphic imagery rendering all types of effects, from sand, to leather, to rain drops. These coatings and varnishes are typically colorless, though tints and specialty pigments can be added.

Soft Touch and Hi Rise coatings are clear coatings that are applied to the exterior surface of otherwise conventional paperboard folding cartons. Soft touch is frequently applied as a flood coating, covering the entire substrate surface, yielding a soft, velvet texture. Hi Rise coatings are typically patterned, often complimenting the graphics of a carton with a glossy, raised pattern. These coatings may also be combined with traditional protective coatings or varnishes, though when applied as a flood coating, Soft Touch would typically replace a traditional coating. Both Soft Touch and Hi Rise can be used independently or together, to achieve different effects on the carton surface. They may be applied inline on the printing press or offline, depending on a converters equipment mix.

Today, consumers demand more (Stutzman, et al., 2012). Among a sea of competitive products, Consumer Products Goods companies (CPGs) look to differentiate their products on the store shelf by engaging more senses and adding texture to the package. Sensory marketing is the new focus. But just how is that done?

The purpose of this study is to determine consumer preference of tactile coatings in packaging at the point of sale. Marketing executives seek new techniques to attract the consumer's attention during new product evaluation. New strategies and new effects are desirable for CPGs to continue to grow market-share. This research focuses on tactile coatings and whether they are effective in attracting the consumer's attention.

A choice-based conjoint study was conducted to determine shoppers' preferences of different beauty and cosmetic product packages containing tactile and non-tactile printing techniques. Data was collected for the respondents' demographic profile, shopping frequencies, agreement to statements about cosmetic packaging and respondents' preferences of various packaging samples.

\section{BACKGROUND AND RELATED LITERATURE}

Packaging printers and converters have been embossing paperboard for years. But embossing is a postpress, and therefore expensive process, utilizing costly tooling and often slower processing speeds. Further, embossing is not possible on 
all substrates. Tactile varnishes, such as Hi Rise, sometimes called high-volume UV, provide texture without the challenge or expense of embossing. More textures are available now than ever before, thanks to advanced production techniques. SAPPI demonstrated numerous Hi Rise techniques in The Standard No 5: Special Effects publication (SAPPI Fine Paper, 2011).

Hess, et al. (2014) studied the impact of packaging quality on brand perception. Their research demonstrated bottle quality for bottled water impacts post-consumption experience evaluations, brand evaluations and subsequent behavioral intentions. Abdalkrim and AL-Hrezat (2013) studied the role of packaging in consumers' perception of product quality in Jordan. Their research found that statistically, the package plays a significant role in promoting products.

Peck and Shu (2009) found that touching an object increases the feeling of perceived ownership. "We find that merely touching an object can increase a nonowner's feeling of perceived ownership and consequently object valuation" (p. 435). Frost (2006) pointed out that containers tend to make conscious tactile appeals to consumers. He found this particularly true for fragrance containers, as well as other cosmetics. Underhill (1999) stated that almost all unplanned shopping is a result of touching, hearing, smelling or tasting something in the store, something that shoppers love to do.

Peck and Childers, (2006) found that when a point of purchase sign encouraged shoppers to touch the packaging using phrases like "feel the freshness," shoppers would purchase more impulsively. According to Lindstrom (2005), brands that appeal to multiple senses will bemore successful than brands that focus only on one or two. Many credit Lindstrom with coining the term "sensory branding."
The analysis method used in this study was choice modeling. It is widely used in market and consumer research as a technique to determine subject preferences among multiple attributes. Choice modeling, pioneered by McFadden (1974), is an analytic method used to estimate the probability of individuals making a particular choice from presented alternatives. Choice modeling is also called conjoint modeling, discrete choice analysis, and conditional logistic regression (JMP ${ }^{\circledR} 11$ Consumer Research, 2014).

In addition to preference of colors and features, choice modeling often incorporates a pricing attribute. This methodology attempts to determine if subjects not only prefer an attribute, but are willing to pay a premium for that attribute.

As new production techniques are developed, CPGs seek market research to validate consumer preferences for these new packaging effects. Do consumers prefer tactile coatings in beauty and cosmetic packaging? In an effort to better understand the desirability of these effects, a set of hypotheses were developed that focused on coating attribute, color and premium pricing.

\section{HYPOTHESES}

Five hypotheses were developed and tested in this research:

- H1 - Consumers prefer Soft Touch tactile packaging over packaging with no tactile coatings.

- H2 - Consumers prefer Hi Rise tactile packaging over packaging with no tactile coatings.

- H3 - Consumers are willing to pay 5\% price in- 
creases for packaging with Soft Touch tactile coatings over packaging with no tactile coatings.

- $\mathrm{H} 4$ - Consumers are willing to pay 5\% price increases for packaging with Hi Rise tactile coatings over packaging with no tactile coatings.

- H5 - Consumers prefer black packaging for beauty and cosmetics packaging over white packaging.

These hypotheses were derived to primarily focus on the two coating attributes: Soft Touch and Hi Rise. However, a 5\% price premium was also considered to determine if consumers prefer one or more attributes enough to pay more for that attribute. A hypothesis was also developed to consider the impact of color on consumer preference and whether there were any interactions between color and the different coating attributes. Soft Touch and Hi Rise have slightly different visual effects on black and white packages.

\section{RESEARCH METHODOLOGY}

A choice-based conjoint study was designed. A convenience sampling of 400 purchasers of beauty and cosmetics products were interviewed to determine demographic profiles and to collect preferred choice data about tactile coatings in packaging. The interviews took place over six weeks from May 22, 2014 to July 3, 2014. Interviews were completed in the retail area of San Luis Obispo, California, commonly referred to as "downtown." Data was gathered by a research team primarily comprised of students from Cal Poly's Graphic Communication Department and the Technical Association of Graphic Arts student chapter.

The subjects interviewed ranged in age from 1864 years. According to the 2012 US Census, the population of 20-64 year olds in San Luis Obispo County is 169,023 , with the population of females in that range at 78,159 (U.S. Census Bureau, 20082012). A confidence level of $95 \%$ with a margin of error of 5\% was achieved with the sample of 400. While the convenience sample consisted of a significantly higher percentage of females, the researchers chose to interview only respondents who acknowledged purchasing beauty and cosmetics products within the past three months.

Fictitious skin foundation packages with various conventional and specialty coating effects were shown to participants, using paired selections (Figure 1). The interviews were designed to determine three things: 1) the appeal of the tactile
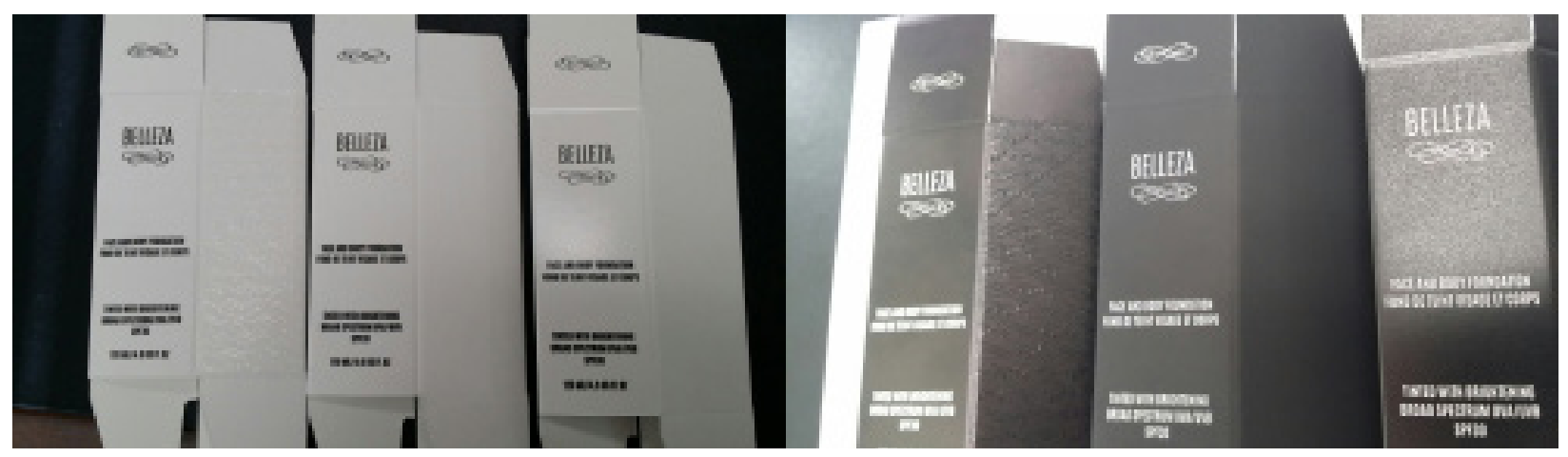

Figure 1 - Photos of fictitious packages in white and black designs with Hi Rise (left), Soft Touch (middle) and no coating. 
coating effect; 2) how shopping preferences are influenced by the coating effect; and 3) the participants willingness to pay a premium for products packaged with these effects.

Demographic data was collected for: gender, age, household income, and residence. Additional questions focused on buying habits for beauty and cosmetic products, as follows:

- In the past three months, approximately how many beauty/cosmetic products have you purchased in the following price ranges? Price categories included:

- $\$ 9.99$ or less,

- $\$ 10.00-\$ 24.99$

- $\$ 25.00-\$ 49.99$

- $\$ 50.00-\$ 74.99$

- $\$ 75.00-\$ 99.99$

- $\$ 100.00+$

- Where do you prefer to purchase these products? Subjects were asked to indicate if they purchased these online or in a retail environment.

Finally, subjects were asked to indicate where they purchased these products for each price category:

- $\quad$ Superstore/web site (Walmart, Target, etc.)

- Department store/website (Macys, Nordstrom, etc.)
- Specialty cosmetic store/web site (Sephora, Ulta, etc.)

- Salon/spa (or web site)

- Other

The survey also asked respondents about their level of agreement with the following four statements, using a 5-point Likert scale:

- When evaluating new beauty/cosmetic products at a retail store, salon or spa, I often pickup and handle the package before purchasing.

- When evaluating new beauty/cosmetic products at a retail store, salon or spa, the packaging influences my purchase (i.e. graphics, imagery, shape, color, texture).

- High quality beauty/cosmetic products have fashionably decorative, expensive packaging.

- When evaluating new beauty/cosmetic products, I often assume that fashionably decorative, expensive packaging is an indication of quality and expect to pay more for the product.

The following experimental attributes were used for the choice-based conjoint design:

\begin{tabular}{|l|l|l|l|}
\hline Attribute & Level 1 & Level 2 & Level 3 \\
\hline Design & Design A & Design B & -- \\
\hline Tactile Coating & No Coating & Soft Touch & Hi Rise \\
\hline Price & $\$ 52.15$ & $\$ 54.76(5 \%$ increase $)$ & -- \\
\hline
\end{tabular}


All respondents answered identical questions, however four different choice sets were developed, requiring each respondent to choose between six paired packaging sets. The data was analyzed in JMP 11.1 software using the conditional logistics regression, or conditional logit model developed by McFadden (1974) and the bias-corrected maximum likelihood estimator described by Firth (1993). JMP is a business unit of SAS that produces interactive software for statistical analysis (SAS Institute, 2014).

JMP's choice model is expressed as:

- Let $\mathrm{X}[\mathrm{k}]$ represent a subject attribute design row, with intercept

- Let $Z[j]$ represent a choice attribute design row, without intercept

- The probability of a given choice for the k'th subject to $\mathrm{j}$ 'th choice of $\mathrm{m}$ choices is:

$$
P_{i}[j k]=\frac{\exp \left(\beta^{\prime}(X[k] \otimes Z[j])\right)}{\sum_{l=1}^{m} \exp \left(\beta^{\prime}(X[k] \otimes Z[l])\right)}
$$

Where:

- $\otimes$ Is the Kronecker product

- The numerator calculates for the j'th alternative actually chosen

- The denominator sums over the m choices presented to the subject for that trial

(JMP® 11 Consumer Research, 2014)

\section{DATA COLLECTION AND ANALYSIS}

Data was collected from 400 respondents. The criterion for participation in the study was that respondents had purchased beauty and cosmetic products within the past three months. Females made up $84 \%$ of the respondents. Fifty-five per- cent of the respondents were from San Luis Obispo County with $27 \%$ from outside of California. The remainder were from other California counties. Figure 2 shows $81 \%$ of the 2319 products purchased by the respondents in the past three months were purchased in retail stores. Of those, nearly one-third were purchased in retail establishments like Sephora and Ulta, popular cosmetics stores. Nearly onethird were purchased at a "superstore" like Target or Walmart. For items priced above $\$ 50$, the "superstore" purchases dropped to just $10 \%$, with all other categories gaining equivalently (Figure 3).

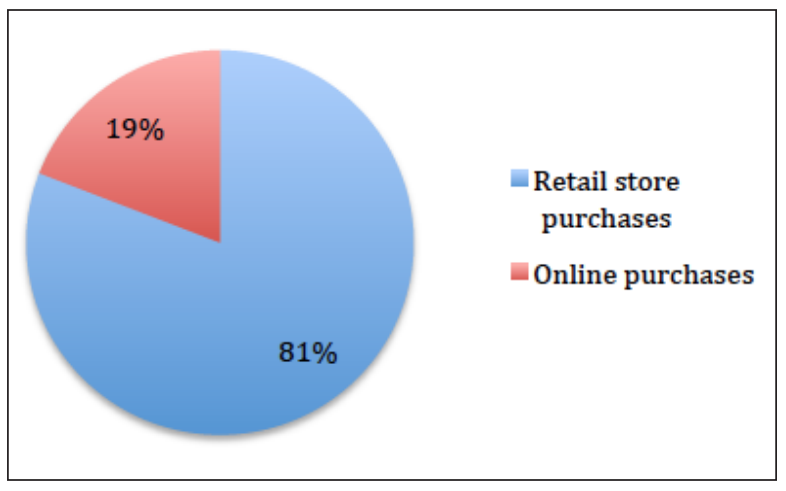

Figure 2 - Distribution of online vs. retail store purchases. 

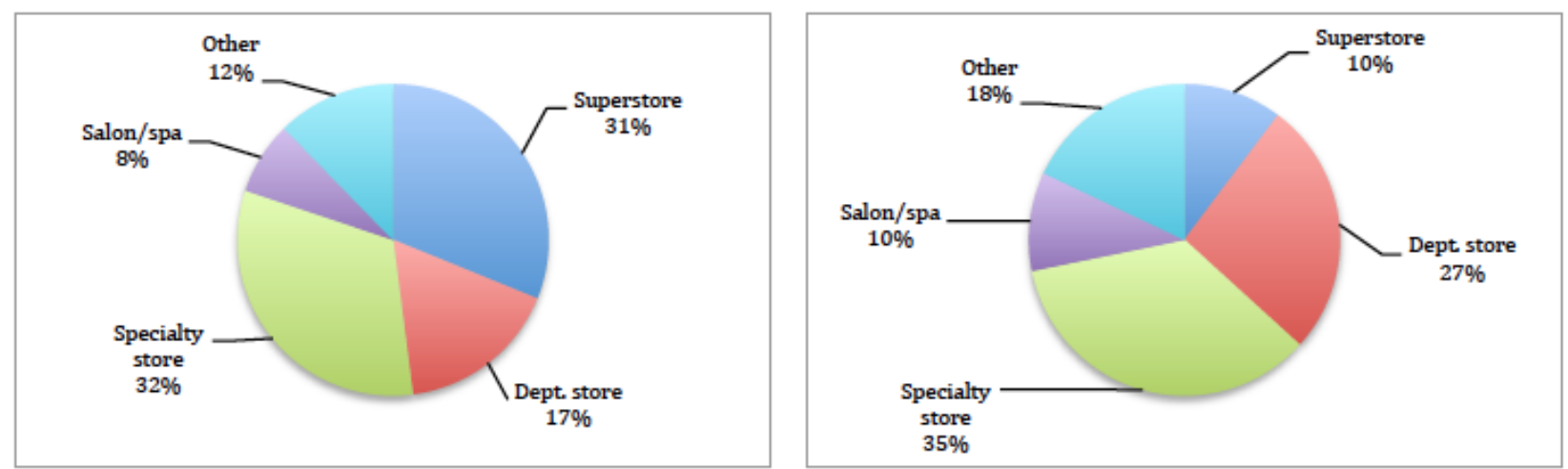

Figure 3 - Breakdown of where products were purchased. Left chart is for all price points and right chart is for products valued $\$ 50$ or more.

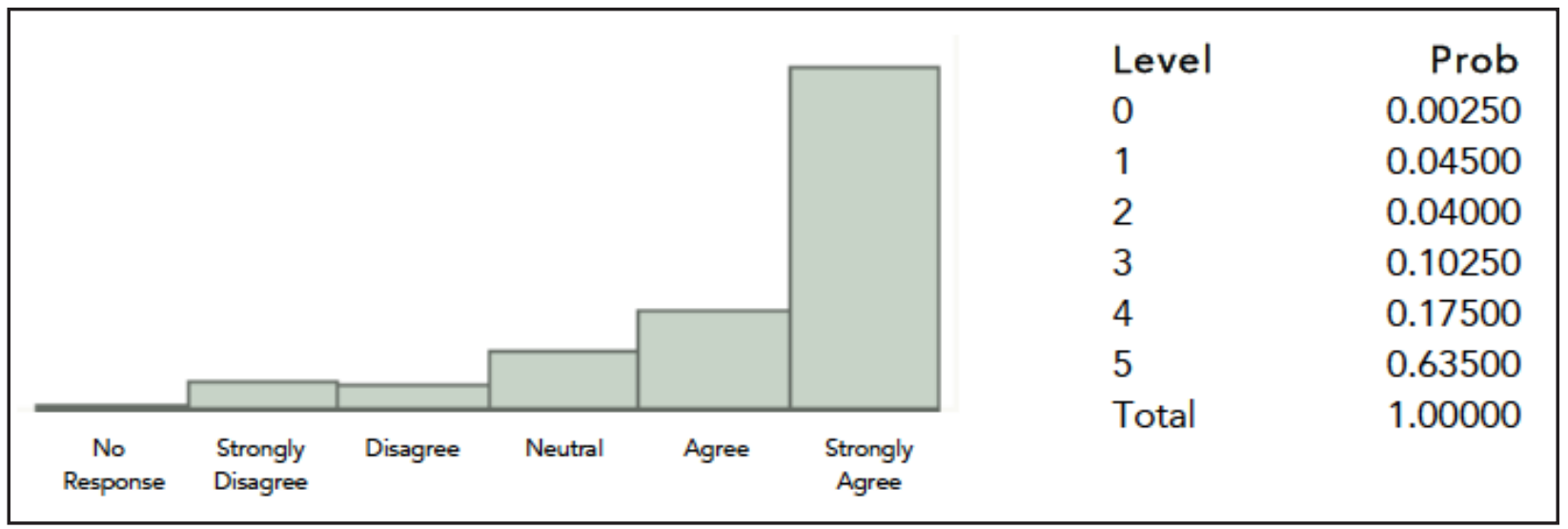

Figure 4 - Level of agreement with statement (0-5) about picking up and handling packaging.

Respondents were asked to indicate their level of agreement with the following statement:

- When evaluating new beauty/cosmetic products at a retail store, salon or spa, I often pickup and handle the package before purchasing.

Sixty three percent of respondents indicated they highly agree with this statement and $17.5 \%$ indicated they agree with this statement. (Figure 4).
Respondents were asked to indicate their level of agreement with the following statement:

- When evaluating new beauty/cosmetic products at a retail store, salon or spa, the packaging influences my purchase (i.e. graphics, imagery, shape, color, texture).

Figure 5 shows that $35 \%$ of the respondents indicated they agree (level 4) with this statement and $24.5 \%$ highly agreed (level 5). 


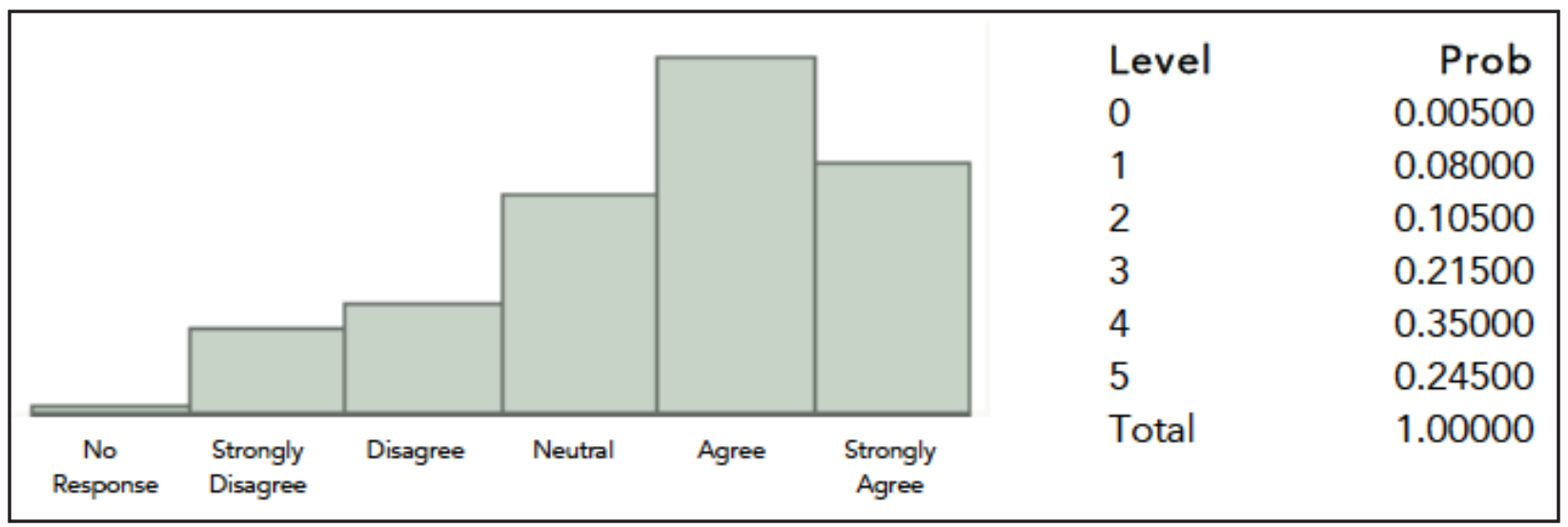

Figure 5 - Agreement level with statement (0-5) that packaging influences purchase.

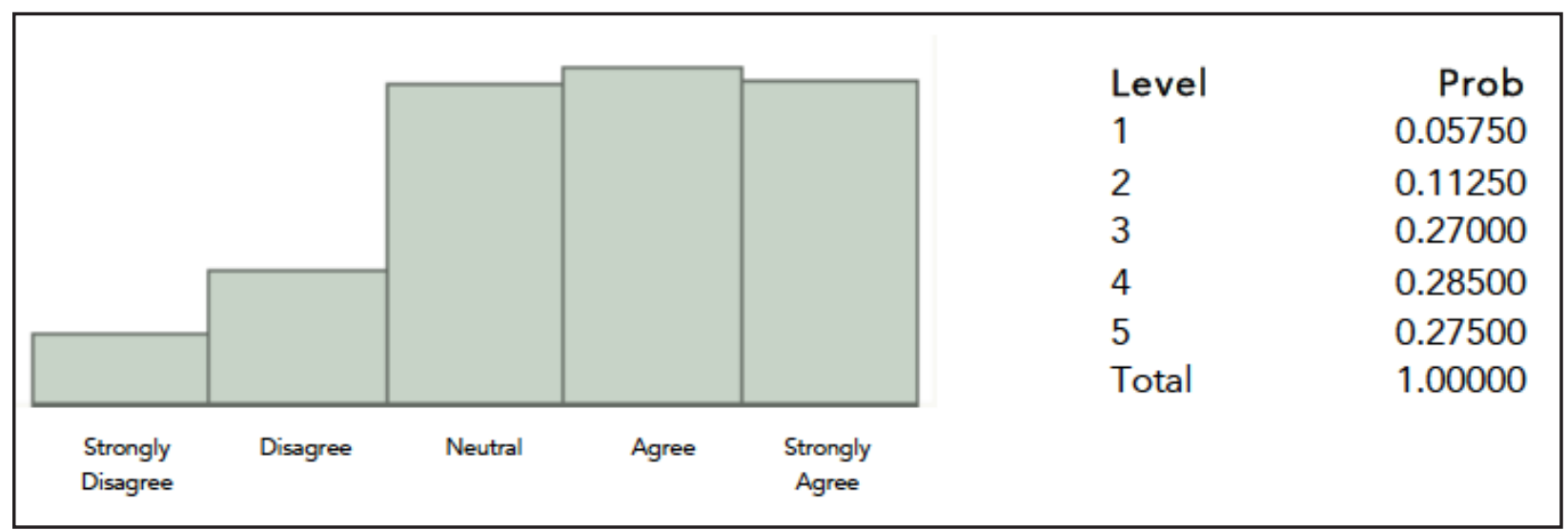

Figure 6-Level of agreement with statement (0-5) that high quality cosmetics have expensive packaging.

Respondents were asked to indicate their level of agreement with the following statement:

- High quality beauty/cosmetic products have fashionably decorative, expensive packaging.

More than half of the respondents indicated they agree (level 4) or highly agree (level 5) with this statement (Figure 6).
Respondents were asked to indicate their level of agreement with the following statement:

- When evaluating new beauty/cosmetic products, I often assume that fashionably decorative, expensive packaging is an indication of quality and expect to pay more for the product.

Forty-five percent of the respondents agreed or highly agreed with this statement (Figure 7). 


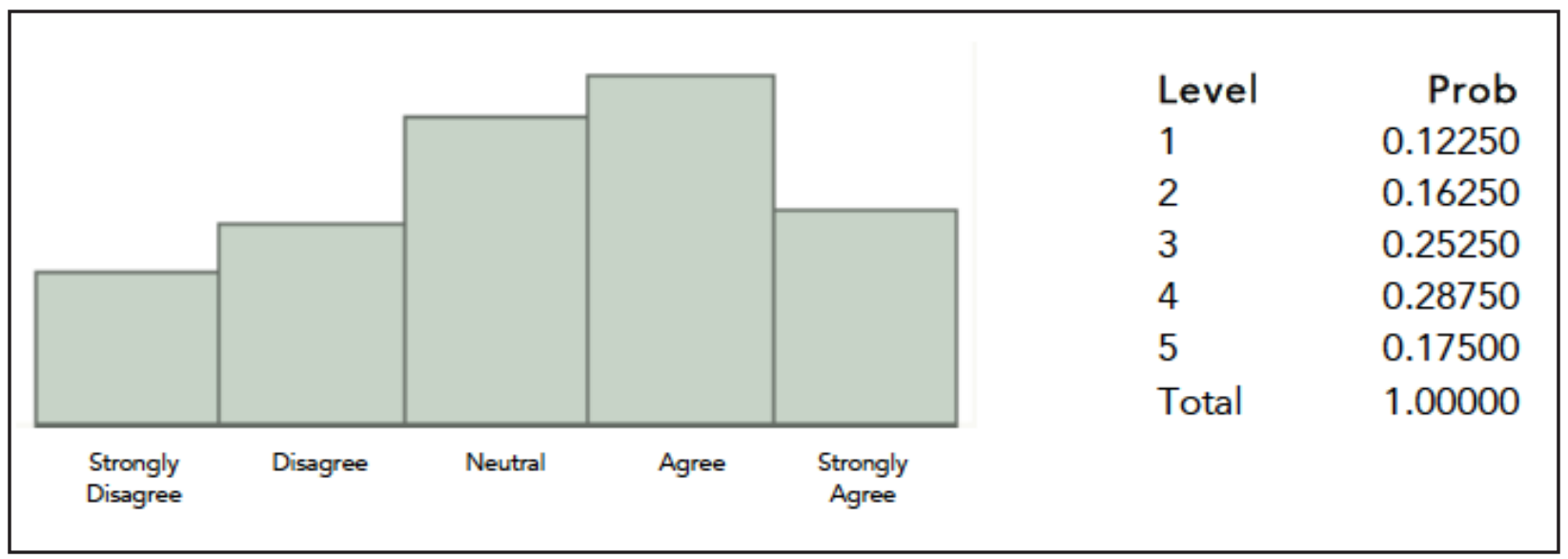

Figure 7 - Level of agreement with statement (0-5) that expensive packaging is an indication of quality.

The tactile coating attribute consisted of three levels: no coating; Soft Touch coating, providing a soft, matte or velvet texture; and Hi Rise coating, simulating a glossy embossed effect that is visible to the eye and may encourage touching. Using choice modeling, the main effects parameter estimates, or part-worths, were computed. These estimates represent the coefficient of utility for each level of each attribute. The higher the parameter estimate, the greater the respondents' value or satisfaction with a specific attribute level. Each row represents the utility for specific attributes when contrasted with a white carton with no coating at the $\$ 54.76$ price. The two prices incorporated in the choice sets were $\$ 54.76$ and $\$ 52.15$, representing a $5 \%$ price differential.

Table 1 shows the Chi2 and Prob $>$ Chi2 values for each attribute. Because the Chi2 for design is very low and the Prob $>$ Chi2 is greater than .05 , we conclude there is no statistical difference between the consumer preference for design colors. H5 is rejected; there is no statistically significant difference in the preference of the black design over the white design in this study. However, because of the relatively high Chi2 values and low Prob $>$ Chi 2 for the other attributes, there is statistical support for one or more hypotheses H1, H2, H3 and H4.

Table 1 - Likelihood Ratio Tests

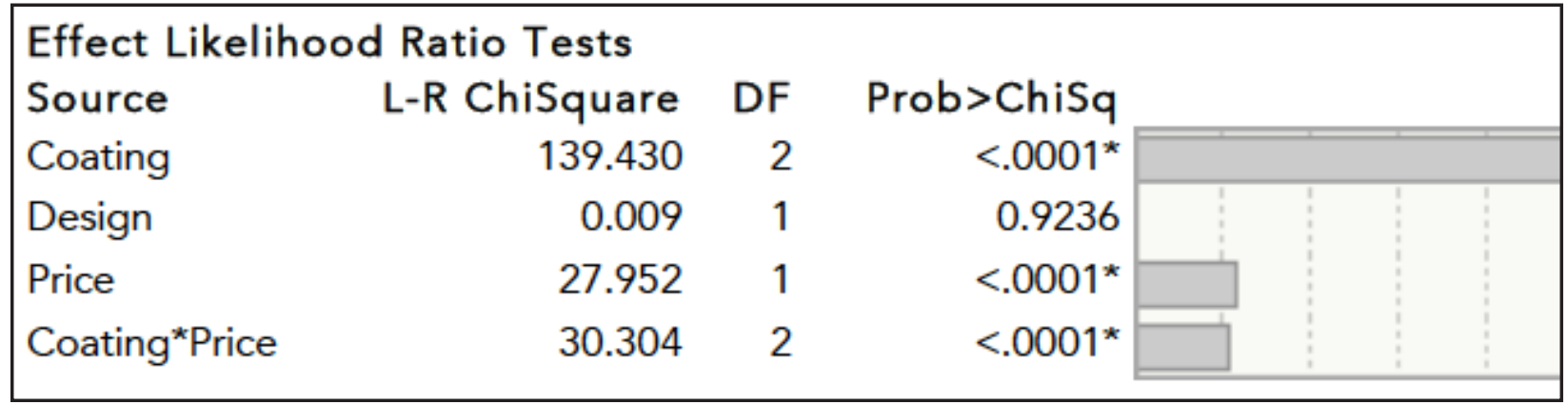


Table 2 - Main effect utility for attributes compared to a white carton with no coating priced at $\$ 54.76$

\begin{tabular}{|l|l|l|}
\hline Term & Estimate & Std Error \\
\hline Coating[Hi Rise] & 0.346962704 & 0.0395187656 \\
\hline Coating[Soft Touch] & 0.028586077 & 0.0339019979 \\
\hline Design[Black] & 0.002372759 & 0.0245259537 \\
\hline Price[\$52.15] & 0.122097560 & 0.0232719137 \\
\hline
\end{tabular}

Table 2 shows the main effect utilities for each attribute and level. A main effect is the impact of one independent variable on the dependent variable, ignoring the effects of all other variables. The parameter estimates indicate that both Hi Rise coating and Soft Touch coating are valued utilities, in contrast to packages with no tactile coating. Consumers prefer these two tactile coatings over no tactile coating.

Hi Rise coating showed a particularly strong parameter estimate, indicating that the tactile coating was especially satisfying or valued to respondents. Respondents preferred the lower price as anticipated and the black versus white designs were split, with minimal preference of one over the other.

A statistical interaction occurs when the effect of one independent variable on the dependent variable changes as the level of another independent variable changes. In this case, we see how the coating utility estimate changes as price changes, results which are of particular interest in market research. Table 3 shows the interactions of coat- ings and price when price is included as a variable with the tactile coatings. Because there was very little preference of the black design over the white design, design interaction is not considered.

The positive number shown for Coating[Hi Rise]*Price [\$52.15] indicates there is a preference for the cheaper price. This is predictable. While respondents preferred Hi Rise coatings the most, their preference is not sustained when introduced with a $5 \%$ price increase. Some price increase is supported, as indicated by the marginal utilities (Table 4), but a price increase of $5 \%$ did not find statistical support.

The negative parameter estimate of the Coating[Soft Touch]*Price[\$52.15] shows that the Soft Touch was not price sensitive like the Hi Rise coating. It demonstrates that Soft Touch coating, though not favored as highly overall as the Hi Rise coating, shows statistical support at the higher price. The data showed that consumers prefer Soft Touch coatings, even when priced 5\% higher than packages with no tactile coating.

Table 3 - Interaction effects for attributes compared to a white carton with no coating at $\$ 54.76$

\begin{tabular}{|l|l|l|}
\hline Coating[Hi Rise]*Price[\$52.15] & 0.311182231 & 0.0570486101 \\
\hline Coating[Soft Touch]*Price[\$52.15] & -0.190023835 & 0.0574215786 \\
\hline
\end{tabular}


Table 4 - Marginal Utilities of Coating*Price Interaction

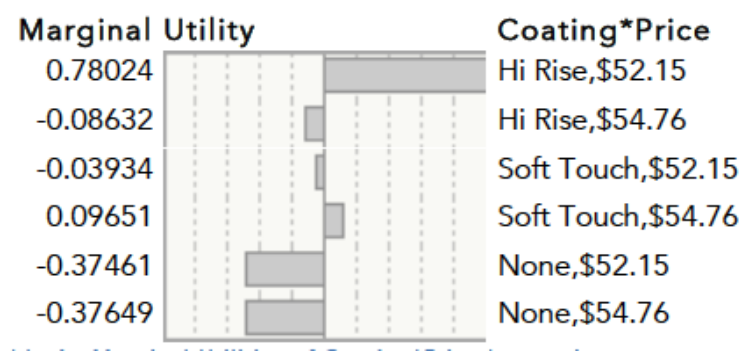

Table 4 provides a graphical representation of the marginal utility of the interactions of the different attributes and levels. Hi Rise coating at the lower price is the preferred choice. Packages without tactile coatings have the least utility at either price. Soft Touch coatings are preferred over no tactile coating and show increased utility at the higher price, indicating increased perceived value.

When interaction utility are ranked by preference, they rank as follows:

1. Hi Rise, $\$ 52.15$

2. Soft Touch $\$ 54.76$

3. Soft Touch $\$ 52.15$

4. Hi Rise $\$ 54.76$

5. No coating, $\$ 52.15$

6. No coating, $\$ 54.76$

Hypothesis H1, consumers prefer Soft Touch tactile packaging over packaging with no tactile coatings, is supported by the 0.335 marginal utility difference between no coating and Soft Touch coating at the lower price. In this study, consumers prefer Soft Touch tactile packaging over packaging with no tactile coatings.

Hypothesis H2, consumers prefer Hi Rise tactile packaging over packaging with no tactile coatings, is supported by a strong 1.154 marginal utility difference between no coating and Hi Rise coating at the lower price. In this study, consumers prefer Hi Rise tactile packaging over packaging with no tactile coatings.

Hypothesis $\mathrm{H} 3$, consumers are willing to pay $5 \%$ price increases for packaging with Soft Touch tactile coatings over packaging with no tactile coatings, is supported by an increase in utility of 0.136 when compared to the Soft Touch utility at the lower price. In this study, consumers are willing to pay $5 \%$ price increases for packaging with Soft Touch tactile coatings over packaging with no tactile coatings.

Hypothesis H4, consumers are willing to pay 5\% price increases for packaging with Hi Rise tactile coatings over packaging with no tactile coatings, is rejected since there is no statistical support as the utility changed by -0.867 . In this study, consumers are not willing to pay $5 \%$ price increases for packaging with Hi Rise tactile coatings over packaging with no tactile coatings. Some price increase is likely supported, but not a $5 \%$ increase.

\section{FINDINGS}

The purpose of this research is to determine the effectiveness of tactile coatings in packaging at the point of sale. Figure 8 shows the relative utility of Hi Rise and Soft Touch for the lower priced black design. The white design would be nearly identical since little preference was indicated between black and white designs. Data analysis shows that the tactile coatings are preferred among the 400 sample respondents examining a fictitious skin foundation package. There was a statistical preference for Hi Rise coating but this tactile effect did not support a 5\% price increase. Some other level below 5\% may be supported, as shown in Figure 9. However, the Soft Touch coating did support a $5 \%$ price increase. 


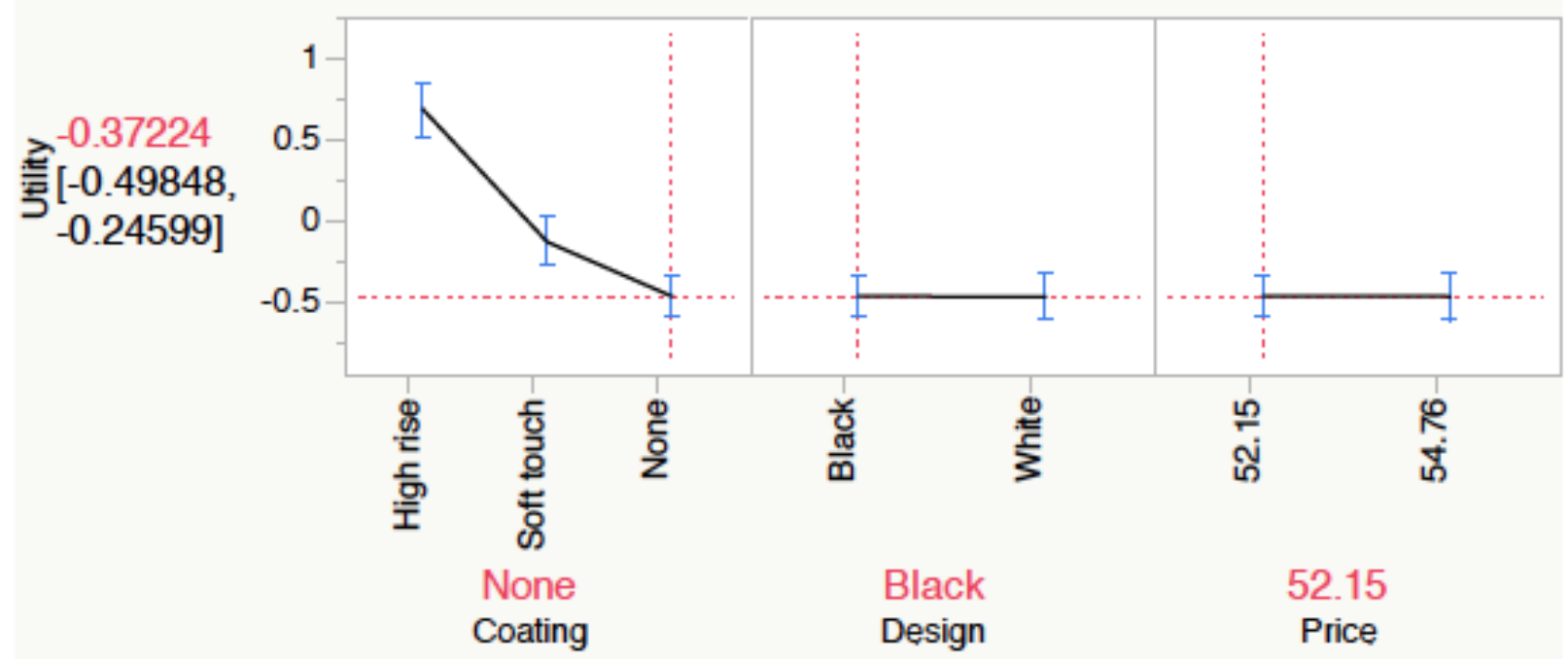

Figure 8-Graphic representation of utility for coatings at $\$ 52.15$ price point.

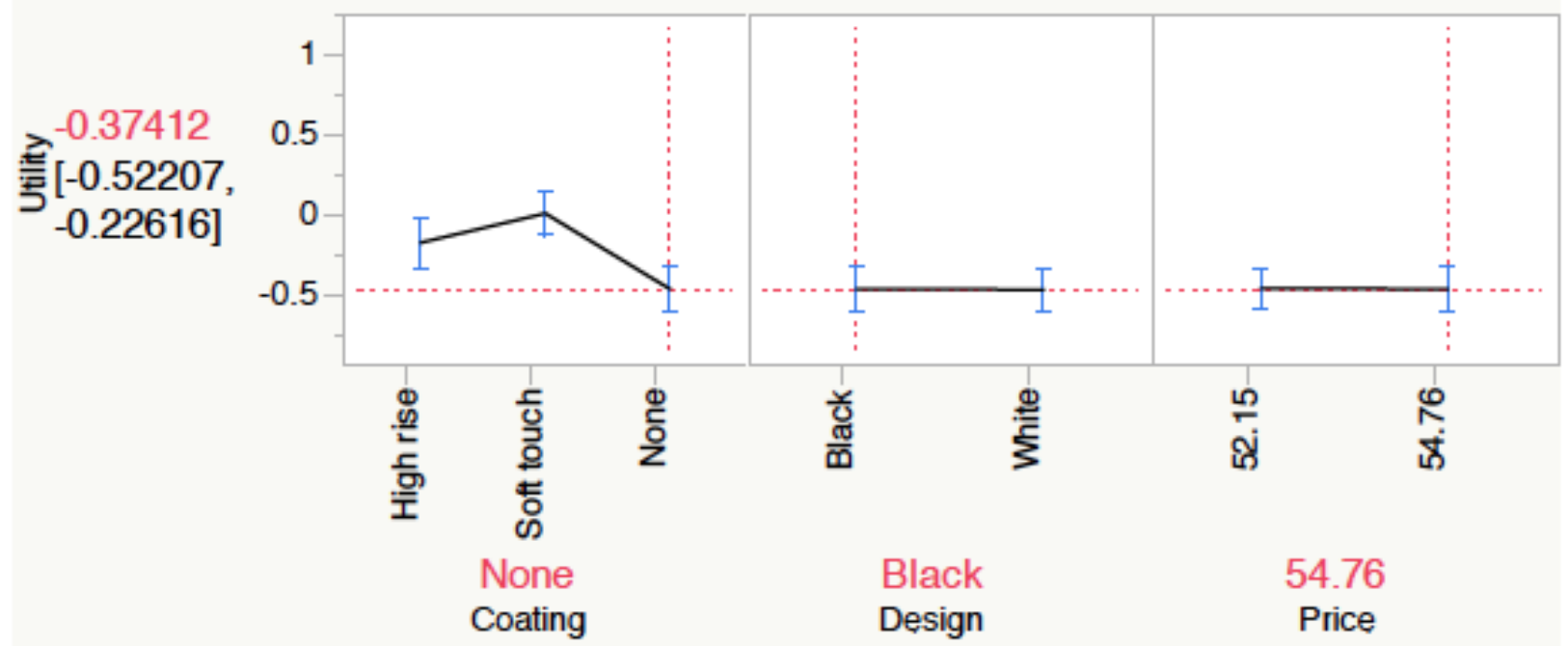

Figure 9 - Graphic representation of utility for coatings at $\$ 54.76$ price point.

The interactions of these independent variables shows that the Hi Rise coating has more favorable tactile appeal but Soft Touch coating indicates a tactile effect that may be perceived by consumers as being of higher quality. Since nearly one-half of the respondents indicated that expensive packag- ing is an indication of quality, this lack of price sensitivity may indicate a greater perceived value connected to the higher price.

It is clear that consumers preferred tactile coatings for the fictitious skin foundation package used in 
this study. Respondents favored both Hi Rise and Soft Touch over packages with no tactile coatings. Further, the Soft Touch preference actually increased as price increased, indicating that consumers may perceive Soft Touch packages to contain products of higher quality.

It should be noted that this study was limited to individuals who self-identify as cosmetics shoppers and reside or visit San Luis Obispo, California.

\section{CONCLUSIONS}

This research provided statistical evidence that consumers in this study preferred Soft Touch and Hi Rise coatings over packaging with no tactile coatings for a fictitious skin foundation product. These findings provide evidence of preference for CPGs who choose to integrate these coatings into their brand strategy through beauty and cosmetics packaging. An increase in tactile coatings used in packaging may result from the favorable response found in this study.

In this study, consumers preferred Soft Touch coatings even at a $5 \%$ price premium. This may help brand owners provide a package that improves its image by appearing to be "more expense." Further, brand owners may be able to increase margins by using packaging with Soft Touch effects.

As shown in this study, choice modeling is a useful way to determine the value of attributes, including their interactions. As new printing techniques are introduced, CPGs will want to explore their appeal to consumers and to test how costumers perceive their value. This study provided evidence that Soft Touch and Hi Rise are valued packaging effects. We expect to see more tactile packaging in stores in the very near future.

\section{REFERENCES}

[7] Abdalkrim, G. M., \& AL-Hrezat, R. S. (2013). The Role of Packaging in Consumer's Perception of Product Quality at the Point of Purchase. European Journal of Business and Management, 5 (4), 69-82.

[8] Firth, D. (1993). Bias Reduction of Maximum Likelihood Estimates . Biometrika , 80 (1), 27-38.

[9] Frost, R. (2006, February 20). Feeling your way in a global marketplace. Retrieved August 1, 2014, from Brand Channel: http:// www.brandchannel.com/features_effect. asp?pf_id=302

[10] Hess, J. S., Singh, J., Metcalf, L. E., \& Danes, J. (2014). The Impact of Consumer Product Package

[11] Quality on Consumption Satisfaction, Brand Perceptions, Consumer Investment and Behavior. Journal of Applied Packaging Research , 6 (1), Article 4.

[12] JMP® 11 Consumer Research. (2014). Consumer Research. Cary, NC: JMP, A Business Unit of SAS.

[13] Klatzky, R. L., \& Peck, J. (2012). Please Touch: Object Properties that Invite Touch. IEEE TRANSACTIONS ON HAPTICS , 5 (2), 139-147.

[14] Lindstrom, M. (2005). Brand Sense. New York, NY: Free Press.

[15] McFadden, D. (1974). Conditional Logit Analysis of Qualitative Choice Behavior. In e. P. Zarembka, Frontiers in Econometrics (pp. 105-142). New York: Academic Press.

[16] Peck, J., \& Childers, T. L. (2006, January). If I touch it I have to have it: Individual and environmental

[17] influences on impulse purchasing. Journal of Business Research .

[18] Peck, J., \& Childers, T. L. (2003). The 
Influence of Haptic Information on Product Judgments . Journal of Marketing , 67 (2), 25-48.

[19] Peck, J., \& Shu, S. B. (2009). The Effect of Mere Touch on Perceived Ownership. Journal of Consumer Research , 36 (3), 434447.

[20] Peck, J., \& Wiggins, J. (2006). It Just Feels Good: Customers' Affective Response to Touch and Its Influence on Persuasion. Journal of Marketing , 70, 56-69.

[21] Saastamoinen, I. (2012). Touch and Feel - The Role of Tactile Qualities on Board Packages. Helsinki,

[22] Sweden: University of Helsinki, Department of Economics.

[23] SAPPI Fine Paper. (2011). The Standard No. 5: Special Effects. Boston, MA, USA: SAPPI Fine Paper, North America.

[24] SAS Institute. (2014, September 4). About Us. Retrieved September 4, 2014, from JMP: http://www.jmp.com/about/

[25] Stutzman, C., Munchbach, C., Cooperstein, D. M., \& Hayes, A. (2012). Consumers Demand More From 21st Century Brands. Cambridge, MA: Forrester Research, Inc.

[26] U.S. Census Bureau. (2008-2012). State \& county Quickfacts: San Luis Obispo County, California. Retrieved April 27, 2014, from American Community Survey: http://quickfacts.census.gov

[27] Underhill, P. (1999). Why We Buy? The science of shopping. New York, NY: Simon and Schuster.
Follow this and additional works at: http://scholarworks.rit.edu/japr

Part of the Book and Paper Commons, Graphic Design Commons, Marketing Commons, Other Business Commons, Product Design Commons, Sales and Merchandising Commons, and the Technology and Innovation Commons

This Article is brought to you for free and open access by RIT Scholar Works. It has been accepted for inclusion in Journal of Applied Packaging Research by an authorized administrator of RIT Scholar Works. For more information, please contact ritscholarworks@rit.edu. 
